\title{
Analisis Teknik Permainan Gitar Klasik Pada Komposisi Gran Vals Karya Fransisco Tarrega
}

\author{
Dwi Rian Saputro \\ Program Studi Seni Musik, Fakultas Bahasa dan Seni, Universitas Negeri Surabaya \\ dwiriansahputra@gmail.com
}

\begin{abstract}
This study aims to: (1) describing classical guitar playing techniques as a whole in Gran Vals compositions by fransisco tarrega; (2) describes the technique of playing difficult classical guitar in the composition of Francisco Tarrega Gran Vals. This study used descriptive qualitative method. Where data is obtained by observation, interviews, documentation, and literature studies. Observations are made by playing, listening, and analyzing these Gran Vals compositions in depth. Interviews were conducted with highly credible speakers in the field of playing classical guitar, Rahmat Raharjo. S.Sn., L.Mus.A., as a classical guitar lecturer at ISI Yogyakarta. The documentation in this study is full score and recordings of Gran Vals composition, both obtained from highly trusted sources, namely Bradford Warner Guitar Editions. Library studies are obtained by searching data through documents both in writing and electronic documents. The results of this study show that the composition of the Francisco Tarrega Gran Vals is a single form composition with rhythmic waltz which has 5 parts in it (A-B-C-DE) with a number of times 119. The technical description of the composition is divided into two parts, namely: (1) overall game techniques that include apoyando and tandoo picking techniques, glissando techniques, slur techniques, and barre techniques. (2) difficult techniques found in Gran Vals compositions which include speed in slur techniques that have their own level of difficulty. Power in many voiceing techniques is found in section C. Economic Movement on barre techniques and effectiveness and efficiency of searching
\end{abstract}

Keywords: Analysis, Playing Technique, Classical Guitar, Gran Vals, Francisco Tarrega

\begin{abstract}
Abstrak
Penelitian ini bertujuan untuk: (1) Mendeskripsikan teknik permainan gitar klasik secara keseluruhan pada komposisi Gran Vals karya Fransisco Tarrega; (2) Mendeskripsikan teknik-teknik permainan sulit pada komposisi Gran Vals karya Fransisco Tarrega ini beserta cara mengatasinya bagian tersebut. Penelitian ini menggunakan metode deskriptif kualitatif. Dimana data diperoleh dengan cara observasi, wawancara, dokumentasi, dan studi pustaka. Observasi dilakukan dengan cara memainkan, mendengarkan, dan menganalisis komposisi Gran Vals ini secara mendalam. Wawancara dilakukan dengan narasumber yang sangat kredibel dalam bidang teknik permainan gitar klasik yaitu Rahmat Raharjo. S.Sn.,L.Mus.A., selaku dosen gitar klasik di ISI Yogyakarta. Dokumentasi pada penelitian ini berupa full score dan rekaman permainan komposisi Gran Vals, keduanya didapat dari sumber yang sangat terpercaya yaitu Bradford Warner Guitar Editions. Studi pustaka didapat dengan pencarian data melalui dokumen-dokumen baik secara tertulis maupun dokumen elektonik. Adapun hasil dari penelitian ini menunjukan bahwa komposisi Gran Vals karya Fransisco Tarrega ini merupakan komposisi dengan bentuk tunggal berirama waltz yang mempunyai 5 bagian didalamnya (A-B-C-D-E) dengan jumlah birama 119. Deskripsi teknik pada komposisi ini dibagi menjadi dua bagian yaitu: (1) teknik permainan secara keseluruhan yang meliputi teknik memetik apoyando dan tirando, teknik glissando, teknik slur, dan teknik barre. (2) teknik sulit yang terdapat pada komposisi Gran Vals ini yang meliputi speed dalam teknik slur yang mempunyai tingkat kesulitan tersendiri. Power dalam teknik voiceing yang banyak terdapat pada bagian C. Economic Movement pada teknik barre serta keefektifan dan keefisienan penjarian yang hampir terletak pada semua bagian komposisi Gran Vals.
\end{abstract}

Kata Kunci: Analisis, Teknik Permainan, Gitar Klasik, Gran Vals, Fransisco Tarrega 


\section{PENDAHULUAN}

Gitar merupakan alat musik petik yang paling popular hingga saat ini. Hal itu dapat dilihat dari banyaknya orang yang mampu memainkan alat musik tersebut. Gitar bisa dikatakan mempunyai peminat yang merata diseluruh penjuru dunia dari kalangan atas hingga kalangan bawah tanpa terkecuali. Gitar sendiri terdiri dari beberapa jenis diantaranya ialah gitar klasik, gitar akustik dan gitar elektrik dari beberapa jenis tersebut gitar klasik mempunyai tempat tersendiri dikalangan pecinta dan penikmat gitar. Hal itu karena gitar klasik mampu menghasilkan bunyi yang sangat indah bagi para penikmatnya. Selain itu gitar klasik juga bisa dikatakan mempunyai tingkat kesulitan paling tinggi untuk memainkanya. Sehingga hal itu menarik orang untuk mempelajari alat musik tersebut secara mendalam.

Gitar klasik mempunyai sejarah yang panjang hingga dapat dikenal dan sepopuler saat ini. Banyak pendapat berbeda yang mengemukakan tentang sejarah kemunculan gitar klasik. Gitar klasik dapat ditelusuri hingga 3000 tahun kebelakang sebelum masehi dimana di peradaban mesir kuno terdapat alat musik Lyra. Instrumen kuno ini mempunyai sebuah badan dengan beban pada leher yaitu dua lengan yang mengarah keatas. Kedua ujung lengan dihubungan dengan jembatan yang berfungsi untuk mengikatkan senarnya. Pada tahun 476M alat musik ini dibawa oleh bangsa Romawi ke Spanyol dan bertransformasi menjadi: (1) guitarra Morisca yang berfungsi sebagai pembawa melodi, dan (2) Guitarra Latina untuk memainkan akor. Tiga abad kemudian bangsa Arab membawa semacam gitar gambus dengan sebutan al ud ke Spanyol (Summerfield, 1982:12).

Beberapa komponis yang menciptakan karya-karya untuk gitar klasik antara lain seperti, Francisco Tarrega dengan karyanya Capricho Arabe, Fernado Sor dengan karyanya Op. 43 Bagatelle No. 3, Dioniso Aguado dengan karyanya Rondo in a minor, Luis de Milan dengan karyanya
Pavane, Ferdinando Carulli dengan karyanya Waltz In E Major, dan lain-lain. Fransisco Tarrega (1852-1909) merupakan komponis, gitaris dan sekaligus seorang pianis di era romantik. Musik era romantik memiliki gaya atau karakter yang berbeda dengan musik di era sebelumnya. Runtuhnya kekuasaan monarki menyebabkan para komponis tidak lagi bekerja pada istana dan lebih bebas untuk menentukan karya apa yang akan dikomposisi. Selain itu, komponis lebih independen serta tidak bergantung lagi kepada istana dan gereja. Hal ini jelas sangat berbeda dengan di era sebelumnya seperti J.S Bach yang membuat karya untuk mengiringi jamuan makan kenegaraan atas pesanan raja atau pun Mozart yang harus meminta persetujuan raja untuk mementaskan operanya.

Fransisco Tarrega mengawali menulis reportoar gitar klasik dengan cara mentranskip karya-karya dari era sebelumnya seperti karyakarya dari Bach, Mozart dan Beethoven ia transkip ke dalam bentuk reportoar gitar klasik sebelum akhirnya menulis karyanya sendiri. Hal seperti ini banyak ditirukan oleh gitaris-gitaris klasik di generasi selanjutnya seperti Caprice no. 24 karya N. Paganini merupakan musik instrumental format solo gitar yang diaransemen oleh John Williams yang merupakan salah satu gitaris terbaik di dunia. (Suwahyono, 2005:25). KaryaKarya Fransisco Tarrega yang berhasil dipublikasikan diantaranya ialah 78 karya original untuk solo gitar, 120 transkrip untuk solo gitar dan 21 transkrip untuk duet gitar klasik. Salah satu karya Agung beliau yang sangat terkenal dan populer hingga saat ini ialah Waltz In A Major atau biasa dikenal dengan Gran Vals. Di ciptakan pada Tahun 1902 karya ini bisa dikatakan sebagai karya dengan irama waltz yang paling popular sampai saat ini khususnya untuk reportoar gitar klasik bahkan karya ini tidak kalah popular jika dibandingkan dengan karya-karya Fransisco Tarrega yang lainya misal seperti Capricho Arabe, Recuerdos De La Alhambra dan Lagrima. 
Waltz sendiri ialah irama musik dengan sukat 3/4 yang sudah ada sejak pertengahan abad ke 18 muncul dalam bentuk awal sebagai musik iringan tari di Vienna kemudian berkembang hingga muncul waltz sebagai musik instrumental murni yang sama sekali bukan untuk iringan tari. Gran Vals Karya Fransisco Tarrega ini merupakan komposisi murni yang diciptakan tanpa ada hal lain selain unsur musikal itu sendiri dan bukan sebagai pengiring dansa atau tari. Jika dilihat kasat mata karya ini seperti tidak memiliki sesuatu yang spesial didalamnya Namun jika mampu menganalisis dengan sungguh-sungguh akan terlihat jelas bahwa karya ini mempunyai tingkat kesulitan yang tinggi dari teknik yang digunakan. Dimana dalam karya ini terdapat cukup banyak teknik permainan yang digunakan. Selain itu terdapat pula banyak bagian-bagian yang sulit untuk dimainkan dengan menggunakan teknik yang berbeda-beda. Seperti teknik Slur yang digunakan dibeberapa bagian. Teknik Barre yang membutuhkan ketepatan, kelenturan dan kekuatan pada tangan kiri serta teknik Voiceing untuk pembagian suara saat membawakan karya ini. Selain harus menguasai teknik-teknik didalam komposisi ini seorang pemain gitar klasik juga harus mempunyai tingkat ketelitian serta kedetailan yang tinggi untuk bisa membawakan karya ini dengan baik.

Gran Vals ini banyak dibawakan oleh para gitaris klasik baik di media sosial youtube maupun dalam konser. Maka dari itu penulis tertarik untuk melakukan penelitian tentang analisis teknik permainan gitar klasik pada komposisi Gran Vals Karya Fransisco Tarrega ini. Untuk dapat mendeskripsikan teknik-teknik permainan pada bagian-bagian teknik sulit yang digunakan dalam karya ini sehingga ketika pemain yang sedang mempelajari karya Gran Vals ini mengalami kesulitan atau menghadapi permasalahan yang tidak dapat dipecahkan sendiri terkait dengan teknik permainannya. Maka penulis telah mendeskripsikan teknik-teknik permainan sulit yang ada pada komposisi ini beserta solusinya melalui hasil penelitian yang telah penulis teliti.

\section{METODE PENELITIAN}

\section{Pendekatan Penelitian}

Penelitian ini merupaan penelitian deskriptif kualitatif, menurut Sugiyono metode penelitian kualitatif ialah:

"metode penelitian yang digunakan untuk meneliti pada kondisi obyek yang alamiah, dimana peneliti adalah sebagai instrument kunci, teknik pengumpulan data dilakukan secara triangulasi (gabungan), analisis data bersifat induktif, dan hasil penelitian kualitatif lebih menekankan makna dari pada generalisasi". (Sugiyono, 2005:1).

Dalam penelitian kuantitatif peneliti menggunakan instrumen untuk meneliti data atau mengukur suatu variable yang diteliti, sedangkan pada penelitian kualitatif peneliti menjadi instrumen (Sugiyono, 2005:2). Metode penelitian seperti ini mengharuskan peneliti mampu menganalisis objek dengan baik sehingga menghasilkan penelitian yang bermakna.

\section{Waktu dan Tempat Penelitian}

Penelitian ini telah dilakukan di rumah peneliti dengan memainkan dan menganalisis partitur Gran Vals karya Fransisco Tarrega. Hal ini karena penelitian ini bukan mengamati fenomena dalam sebuah lingkungan yang membutuhkan lapangan penelitian seperti komunitas, sanggar, dan lingkungan musik lainnya. Sementara itu, penelitian ini telah dilaksanakan selama bulan April tahun 2019 sampai bulan Mei tahun 2019.

\section{Sumber Data Penelitian}

Pengertian sumber data menurut Sugiyono (2009:225) bila dilihat dari sumber datanya, maka pengumpulan data dapat menggunakan sumber primer dan sumber sekunder. Sumber primer adalah sumber data yang langsung memberikan data kepada pengumpul data, dan sumber sekunder merupakan sumber yang tidak langsung memberikan data kepada pengumpul data. Menurut Zuldafrial (2012:46) adalah subjek dari mana data dapat diperoleh. 
Dalam penelitian ini sumber data primer diperoleh dari partitur/full score komposisi Gran Vals karya Fransisco Tarrega dari Bradford Warner Guitar Editions serta dari wawancara bersama ahli yang menguasai teknik permainan gitar klasik, yaitu Rahmat Raharjo, S.Sn., L.Mus.A. Sedangkan sumber data sekunder dalam penelitian ini diperoleh dari Video rekaman permainan komposisi Gran Vals dari Bradford Warner Guitar Editions, buku teknik gitar klasik dari Khitarologus, buku metode permainan gitar klasik dari Bradford Warner Guitar Editions, buku tentang komposisi Fransisco Tarrega beserta buku musik secara umum yang mendukung dalam penelitian ini.

\section{Teknik Pengumpulan Data}

Teknik pengumpual data menurut Sugiyono (2013:224) merupakan langkah yang paling strategis dalam penelitian, karena tujuan utama dari penelitian adalah mendapatkan data. Teknik pengumpulan data yang digunakan dalam penelitian ini dimaksudkan untuk memperoleh bahan-bahan, keterangan, atau informasi yang benar dan dapat dipercaya dengan cara pengamatan pendengaran melalui video, analisis, dan observasi. Metode yang digunakan dalam teknik pengumpulan data yaitu observasi, wawancara, dokumentasi, dan studi pustaka. Berikut ini adalah penjelasan beberapa metode tersebut, yaitu:

\section{A. Observasi Partisipasif}

Observasi Partisipasif adalah metode pengumpulan data yang digunakan untuk menghimpun data penelitian melalui pengamatan dan pengindraan dimana observer atau peneliti benar-benar terlibat secara langsung.

Observasi jenis ini digunakan pada penelitian ini peneliti terlibat langsung dengan cara memainkan komposisi Gran Vals ini, dan mengamati pemain gitar klasik yang memainkan karya tersebut. Dengan memainkan Gran Vals karya Fransisco Tarrega ini peneliti dapat sekaligus melakukan proses analisis terhadap teknik-teknik permainan secara keseluruhan serta bagian-bagian yang di anggap sulit dalam komposisi Gran Vals karya Fransisco Tarrega ini.

B. Wawancara semi terstruktur

Wawancara jenis ini adalah wawancara yang pelaksanaannya lebih bebas bila dibandingkan dengan wawancara terstruktur. Tujuan dari wawancara ini adalah untuk menemukan permasalahan secara lebih terbuka, dimana pihak yang diajak wawancara diminta pendapat dan ide-idenya.

Dalam penelitian ini wawancara yang digunakan ialah wawancara semi terstruktur. Menurut Sugiyono (2011:233) wawancara semi terstruktur pelaksanaanya lebih bebas bila dibandingkan wawancara terstruktur, tujuanya untuk menemukan permasalahan secara lebih terbuka. Dimana pihak yang dimintai wawancara diminta pendapat dan ide-idenya.

Dengan teknik wawancara ini diharapkan dapat memperoleh data yang lebih lengkap sesuai kebutuhan dari topik permasalahan. Peneliti telah melakukan wawancara mengenai analisis teknik permainan gitar klasik pada komposisi Gran Vals karya Fransisco Tarrega dengan memilih informan yang dipandang mampu memberikan data yang akurat, yaitu Rahmat Raharjo, S.Sn., L.Mus.A. selaku dosen gitar kalsik di Institut Seni Indonesia Yogyakarta. pada tanggal 19 April 2019. Wawancara pada penelitian ini dilakukan dengan menggunakan pedoman wawancara. Adapun pedoman tersebut dapat dilihat pada table berikut 
Tabel 1 (Pedoman Wawancara)

\begin{tabular}{|c|c|c|}
\hline No & Aspek & Pertanyaan \\
\hline 1. & Teknik & $\begin{array}{l}\text { - Teknik permainan apa } \\
\text { saja yang terdapat pada } \\
\text { komposisi Gran Vals ini } \\
\text { ? } \\
\text { - Bagaimana tingkat } \\
\text { kesulitan teknik } \\
\text { permainan gitar klasik } \\
\text { pada komposisi Gran } \\
\text { Vals ini? } \\
\text { - Bagaimana cara } \\
\text { mengatasi mengatasi } \\
\text { bagian sulita pada } \\
\text { komposisi Gran Vals ini } \\
\text { ? Etude apa saja yang } \\
\text { menunjang dalam } \\
\text { mengatasi bagian sulit } \\
\text { tersebut? }\end{array}$ \\
\hline 2. & Struktur & $\begin{array}{l}\text { - Bagaimana Struktur } \\
\text { dalam komposisi Gran } \\
\text { Vals ini? } \\
\text { - Bagaimana bentuk } \\
\text { komposisi Gran Vals ini } \\
\text { ? }\end{array}$ \\
\hline 3. & Interpretasi & $\begin{array}{l}\text { - Bagaimana interpretasi } \\
\text { teknik pada jaman } \\
\text { Romantik? }\end{array}$ \\
\hline 4. & $\begin{array}{c}\text { Latar } \\
\text { Belakang }\end{array}$ & $\begin{array}{l}\text { - Bagaimana latar } \\
\text { belakang terciptanya } \\
\text { komposisi Gran Vals ini } \\
\text { ? }\end{array}$ \\
\hline
\end{tabular}

\section{Dokumentasi}

Dokumentasi adalah cacatan peristiwa yang sudah berlalu. Dokumen bisa berbentuk, tulisan, gambar, atau karya-karya monumetel dari seseorang. (Sugiyono, 2008:82). Dokumentasi dilakukan untuk pendukung serta pelengkap data hasil dari penelitian Analisis Teknik Permainan Gitar Klasik Pada Komposisi Gran Vals Karya Fransisco Tarrega ini. Dokumentasi pada penelitian ini diambil dari wawacara dengan narasumber yang kredibel dalam bidang gitar klasik, yaitu Rahmat Raharjo, S.Sn., L.Mus.A., full score atau partitur yang diambil dari Bradford Warner Guitar Editions, serta video rekaman permainan komposisi Gran Vals karya Fransisco Tarrega ini dari Bradford Warner Guitar Editions.

\section{Studi pustaka}

Adalah langkah awal dalam metode pengumpulan data. Studi pustaka merupakan metode yang diarahkan kepada pencarian data melalui dokumen-dokumen baik secara tertulis maupun dokumen elektonik. Hasil penelitian juga akan semakin kredibel apabila didukung foto-foto atau karya tulis akademik dan seni yang telah ada. (Sugiyono, 2005:83). Studi Pustaka dalam penulisan penelitian ini diambil dari buku-buku yang berkaitan dengan penelitian Analisis Teknik Permainan Gitar Klasik Pada Komposisi Gran Vals Karya Fransisco Tarrega ini yang diantaranya buku Khitarologus, Classical Guitar Metod Vol.1, The Christopher Parkering Guitar Method, dan Technical Work Book, Gitarpedia, Classical Guitar Metod Vol.2, Guitar Course Book 6, Corso De Guitarra Fundamental dan lain sebagainya.

\section{HASIL DAN PEMBAHASAN}

\section{Bentuk Komposisi Gran Vals karya Fransisco Tarrega}

Gran Vals merupakan salah satu karya untuk gitar klasik yang diciptakan oleh Fransisco Tarrega, yang mana Beliau ialah seorang komponis sekaligus pemain gitar pada periode zaman romantik. Gran Vals ialah komposisi dengan sukat $3 / 4$ berirama waltz yang merupakan salah satu karya terbaik untuk solo gitar klasik yang pernah diciptakan hal ini terbukti dengan masih sangat populernya karya tersebut hingga saat ini dan masih banyak dibawakan oleh para pemain gitar klasik baik dalam konser maupun 
dalam recital. Beberapa gitaris klasik ternama yang pernah membawakan karya ini diantaranya David Russell dan Anika Hutschreuther. Secara keseluruhan Gran Vals ini memiliki 119 birama yang terdiri dari 5 bagian yaitu A-B-C-D-E. Hal ini selaras dengan apa yang disampaikan Rahmat Raharjo dalam wawancara tanggal 19 April 2019 bahwa Gran Vals ini mempunyai bentuk tunggal berirama waltz dengan 5 bagian (section), istilah "bagian" disini harus dibedakan dengan istilah "movement". Bentuk musik waltz seperti ini mirip dengan bentuk musik waltz dari Johann Strauss II yang di dalamnya terdapat banyak bagian berirama waltz, dalam karya Johann Strauss II biasanya memakai istilah Waltz 1, Waltz 2, Waltz 3 dan seterusnya, setelah waltz nomor sekian kembali lagi ke waltz 1 dan ditutup dengan coda.

\section{Struktur Komposisi Gran Vals karya Fransisco Tarrega}

A. Bagian A (3\#)

Bagian A ini Terdapat 33 Birama. Dimulai dengan irama gantung pada birama pertama. Pada bagian in terdapat dua periode yaitu periode A1 dan A2. Periode A1 ini terdiri dari 16 birama, dimulai dengan irama gantung pada ketukan ketiga dibirama pertama. Periode ini terdapat dua frase, frase pertama yaitu pada birama 1-8 yang merupakan frase tanya dan frase kedua pada birama 8-16 yang merupakan frase jawab. Periode A2 ini terdiri dari 16 birama, dimulai dengan birama gantung pada birama ke 17 kemudian diakhiri dengan bentuk akord diketuakan 33 . Periode ini terdiri dari dua frase, frase pertama birama 17-25 yang merupakan frase tanya dan frase kedua pada birama 26-33 yang merupakan frase jawab.

B. Bagian B (4\#)

Bagian ini terdiri dari 18 birama dengan dua periode didalamnya. Periode B1 terdiri dari 8 birama dengan dua frase didalamnya yaitu pada birama 33-37 yang merupakan frase tanya dan frase kedua 37-41 yang merupakan frase jawab.
Sedangkan periode B2 terdiri dari 9 birama. Dengan frase pertama dari birama 41-44 yang merupakan frae tanya. Sedangkan frase kedua yaitu dari birama 45-49 yang merupakan frase jawab.

C. Bagian C (5\#)

Bagian $\mathrm{C}$ ini terdiri dari 15 birama yang dimulai dari birama 52-67. Periode $\mathrm{C} 1$ pada bagian ini terdiri dari 8 birama dengan frase pertama dari birama 52-55 yang merupakan frase tanya. Sedangkan frase kedua yaitu dari birama 56-59 yang merupakan frase jawab. Sedangkan periode kedua terdiri dari 7 birama dengan frase pertama terdiri dari birama 60-62 yang merupakan frase tanya. Sedangkan frase kedua yaitu dari birama 63-67 yang merupakan frase jawab.

D. Bagian D (4\#)

Bagian ini terdiri dari 12 birama dengan dua periode didalamnya. Periode pertama (D1) terdiri dari 8 birama dengan frase pertama terdiri dari birama 69-72 yang merupakan frase tanya. Sedangkan frase kedua yaitu dari birama 73-77 yang merupakan frase jawab. Sedangkan periode D2 terdiri dari 8 birama dengan frase pertama terdiri dari birama 77-80 yang merupakan frase tanya. Sedangkan frase kedua yaitu dari birama 80-85 yang merupakan frase jawab.

E. Bagian E (3\#)

Bagian E ini Terdapat 33 Birama dimulai dengan irama gantung pada birama pertama. Periode pertama pada bagian ini adalah E1 yang terdiri dari 16 birama, dimulai dengan irama gantung pada ketukan ketiga dibirama pertama. Periode ini terdapat dua frase, frase pertama yaitu pada birama 88-94 yang merupakan frase tanya dan frase kedua pada birama 95-103 yang merupakan frase jawab. Sedangkan periode E2 terdiri dari 16 birama, dimulai dengan birama gantung pada birama ke 103 kemudian diakhiri dengan bentuk akord diketukan 119. Periode ini terdiri dari dua frase, frase pertama birama 103110 yang merupakan frase tanya dan frase kedua pada birama 111-119 yang merupakan frase jawab. 


\section{Pembahasan Tingkat Kesulitan Teknik Permainan Gitar Klasik pada Komposisi Gran Vals karya Fransisco Tarrega}

Komposisi Gran Vals ini memiliki tingkat kesulitan yang tinggi dibeberapa bagian sehingga untuk dapat membawakan karya ini dengan baik seorang pemain gitar klasik harus mengetahui serta menguasai beberapa teknik dalam permainan gitar klasik diantaranya: (1) speed dalam teknik slur. (2) power dalam teknik voiceing yaitu pembagian suara antara melodi utama dan iringan. (3) economic movement dalam teknik barre dan penjarian. Berikut ini adalah hasil analisis tentang teknik-teknik sulit yang digunakan dalam kompoisis Gran Vals diantaranya:

\section{A. Speed}

Kecepatan dalam komposisi ini terdapat dalam teknik slur yang terletak di beberapa bagian pada komposisi Gran Vals ini. Di antaranya adalah sebagai berikut:

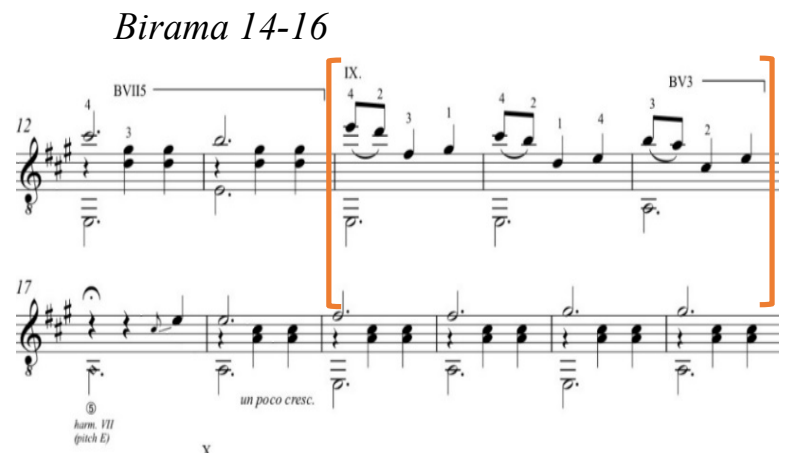

Gambar 1 (Teknik Permainan Slur)

(Sumber: Bradford Warner Guitar Editions)

Pada birama 14-16 ini teknik slur digunakan di bagian melodi utama dengan nilai notasi $1 / 8$. Permasalahan yang bisa terjadi pada bagian ini di antaranya ketukan yang tidak stabil serta teknik slur yang tidak bunyi. Ketukan tidak stabil dalam bagian ini bisa terjadi dikarenakan notasi dalam teknik slur dengan notasi sebelum dan sesudah teknik tersebut mempunyai nilai yang berbeda sehingga diperlukan kontrol ketukan yang baik agar tidak bertambah cepat ataupun bertambah lambat.

Sedangkan untuk teknik slur tidak bunyi bisa terjadi karena pada bagian ini teknik slur diambil oleh jari 3 dan 4 yang biasanya merupakan jari terlemah dari seorang pemain ditambah dengan teknik slur yang memang harus dimainkan dengan cepat.

Birama 33

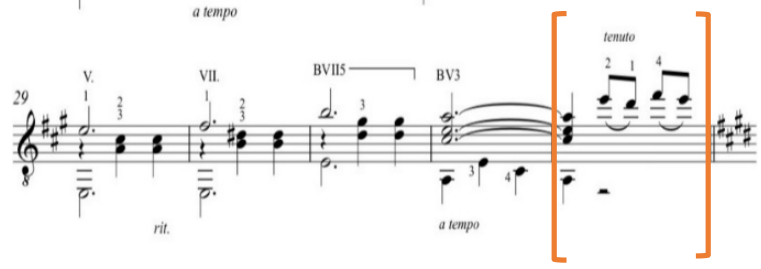

Gambar 2 (Teknik Permainan Slur) (Sumber: Bradford Warner Guitar Editions)

Birama 34-39

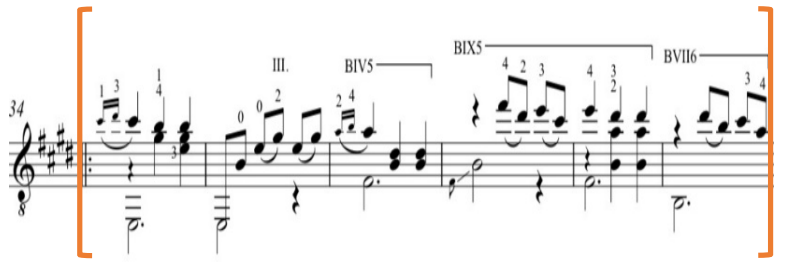

Gambar 3 (Teknik Permainan Slur)

(Sumber: Bradford Warner Guitar Editions)

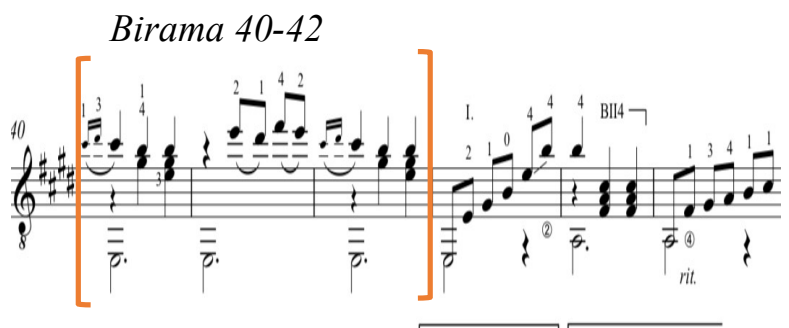

Gambar 4 (Teknik Permainan Slur)

(Sumber: Bradford Warner Guitar Editions)

Pada birama 33-42 teknik slur digunakan sama dengan sebelumnya yaitu digunakan di melodi utama pada komposisi ini yang artinya juga harus menghasilkan suara yang lebih keras. Namun yang membuat bagian ini menjadi sulit ialah posisi teknik slur itu dimainkan, dimana 
teknik ini dimainkan di fret 10,11, 12 dan 14 yang merupakan posisi yang sangat sulit untuk melakukan teknik slur karena terhalang oleh badan gitar itu sendiri. Selain itu notasi tersebut juga mengaruskan jari 3 dan 4 pemain untuk mengambil beberapa bagian dalam teknik slur tersebut. Maka selain faktor penjarian, faktor lain yang dapat mendukung ialah teknik dasar dalam permainan gitar klasik yaitu posisi duduk dan posisi gitar pemain. Hal itu sangat berpengaruh dan mendukung untuk mempermudah pemain dalam memainkan bagian ini.

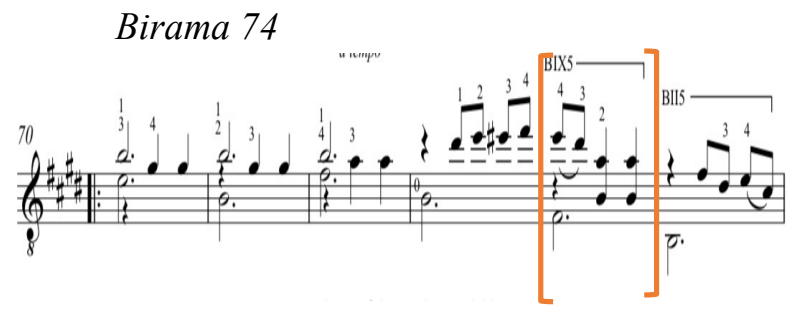

Gambar 5 (Teknik Permainan Slur)

(Sumber: Bradford Warner Guitar Editions)

Pada birama 74 ini sama dengan bagian yang sebelumnya yaitu teknik slur digunakan di melodi utama dengan nilai notasi 1/8. Permasalahan yang bisa terjadi pada bagian ini ialah teknik slur yang tidak bunyi hal itu bisa terjadi karena teknik tersebut dimainkan bersamaan dengan teknik barre. Rinciannya pada birama 74 saat jari 3 dan 4 memainkan teknik slur disaat itu pula jari 1 dalam posisi mengambil teknik barre. secara praktik perpindahan awal jari pemain dari notasi sebelumnya pasti akan lebih kuat di teknik barre sehingga hal itu bisa membuat teknik slur tidak dapat berbunyi dengan maksimal. Untuk dapat mengatasi beberapa teknik sulit pada bagian-bagian tersebut adalah dengan cara sebagai berikut: (1) Pemain harus memainkan bagian ini dengan posisi duduk dan memeggang gitar klasik yang benar. (2) Untuk mengatasi tingkat kesulitan pada bagian ini yang berkaitan dengan kecepatan maka harus dimainkan dengan tempo yang lambat terlebih dahulu. Hal itu agar suara teknik slur yang dihasilkan bisa jelas kemudian kecepatan tempo ditambah secara bertahap. (3) Untuk mengatasi kontrol ketukan pada bagian ini bisa di atasi dengan cara memainkan bagian tersebut menggunakan metronome dari tempo yang paling pelan sampai tempo yang sesuai. (4) Memainkan bagian ini secara berulang-ulang hal ini agar jari pada tangan kiri terbiasa dengan posisi dan perpindahan-perpindahan yang ada. (5) Untuk menguatkan jari-jari tangan kiri dalam memainkan teknik slur pada bagian ini, terutama pada bagianbagian fret yang sulit dapat dilatih dengan menggunakan etude Aaron Shearer No. 4.

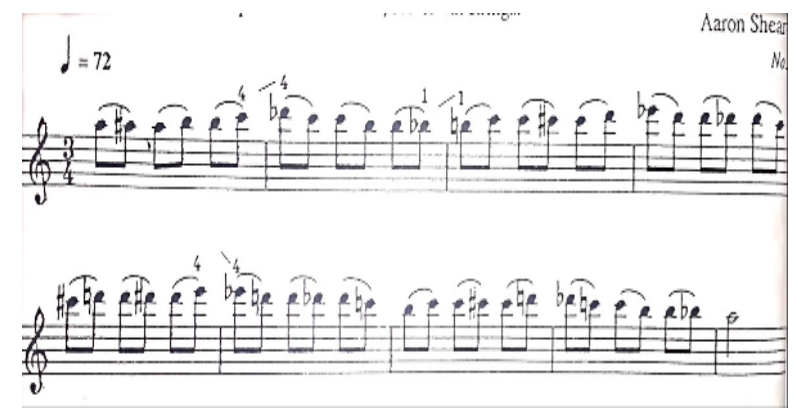

Gambar 6 (Etude Aaron Shearer No. 4 dan No.

9)

(Sumber: Technical Word Book)

Kelima tahapan untuk mengatasi teknikteknik sulit pada bagian ini tentunya juga harus didukung dengan teknik dasar permainan gitar klasik yang baik dari seorang pemain yaitu posisi duduk dan posisi memeggang gitar klasik.

\section{B. Power}

Power adalah kekutan kerasnya suara yang dapat dihasilkan dalam memainkan alat musik. Saat membawakan sebuah reportoar pada gitar klasik seperti Gran Vals ini power merupakan hal yang sangat penting dan harus dikuasai oleh pemain. Power disini tunjukkan untuk teknik voiceing, teknik yang digunakan untuk membagi antara melodi utama dan iringan. Teknik voiceing pada komposisi Gran Vals ini sebenarnya juga digunakan pada seluruh bagian pada komposisi ini. Namun di bagian ini teknik voiceing ini menjadi sulit dilakukan karena pada birama 52-57 (Bagian C) ini suara melodi utama berada pada nada yang rendah (Bass) sedangankan iringan berada pada nada yang lebih tinggi (Treble). Sehingga mengharuskan seorang pemain bisa mengontrol 
antara suara melodi utama dan iringan. Hal ini sependapat dengan yang di sampaikan Rahmat Raharjo dalam wawancara tanggal 19 April 2019. Berikut ini bangian yang membutuhkan teknik Voiceing yang baik dalam memainkanya:

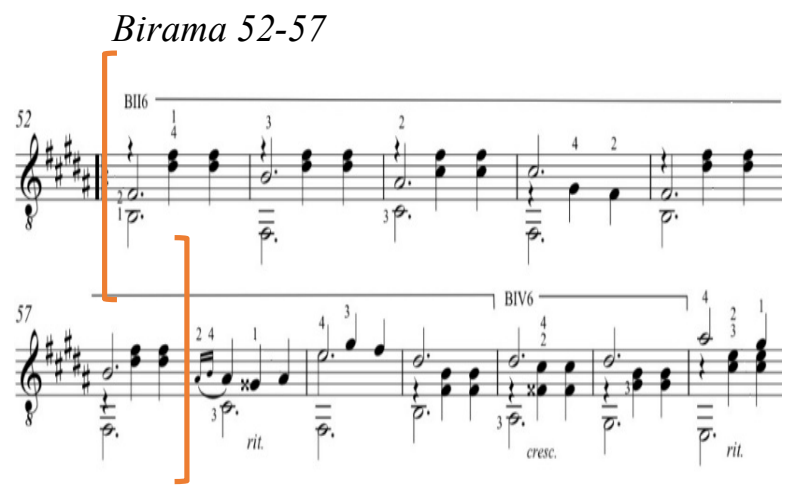

Gambar 7 (Teknik Voiceing)

(Sumber: Bradford Warner Guitar Editions)

Pada birama 52-57 ini terlihat jika melodi utama diambil oleh jempol (p) dan jari telunjuk (i) sehingga mengharuskan jari-jari tersebut dapat menghasilkan suara yang lebih kuat atau lebih menonjol. Sedangkan jari (m) dan (a) berfungsi untuk mengambil nada iringan yang artinya mengharuskan jari-jari kanan tersebut dapat menghasilkan nada yang lebih pelan. Selain itu pada tangan kiri pemain juga diharuskan memainkan teknik barre yang tentunya membutuhkan ketepatan dan kekuatan. Untuk mengatasi bagian ini adalah dengan cara sebagai berikut: (1) Memainkan bagian ini dengan memisahkan antara melodi utama dan iringan dengan tempo yang pelan namun dengan mengedepankan fungsi pada jari-jari tersebut. Jari jempol (p) dan telunjuk (i) dilatih dengan suara yang kuat atau keras sedangkan jari (m) dan (a) dilatih dengan memainkan nada tersebut secara pelan. (2) Memainkan bagian ini secara bersamasama dengan tempo yang lambat. Hal itu agar pemain dapat mengukur perbedaan suara yang dihasilkan antara melodi utama dan iringan. (3) Menguatkan jari tangan kanan pemain dalam memainkan teknik Voiceing dengan cara memainkan etude yang menunjang teknik pembagian suara tersebut. yaitu etude F. Carulli.

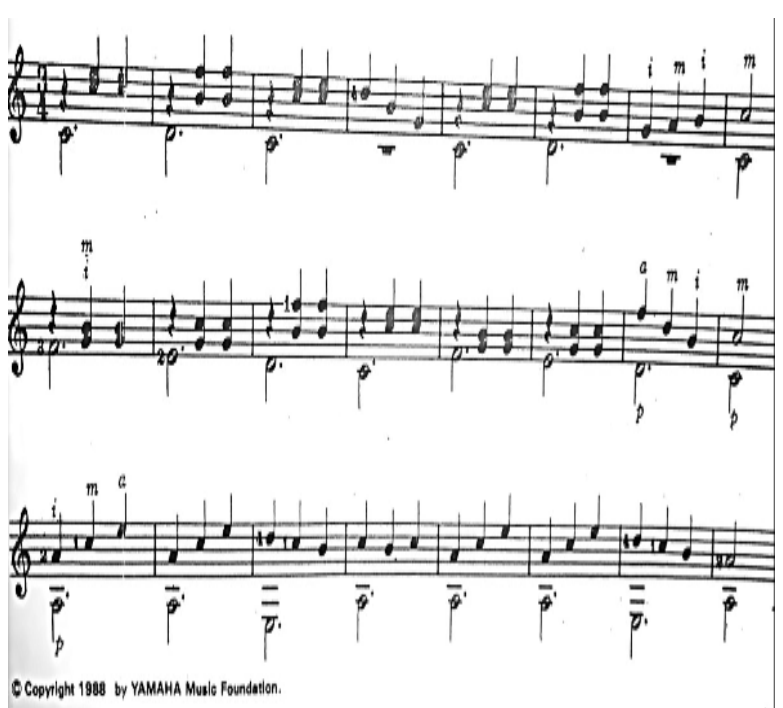

Gambar 8 (Etude F. Carulli)

(Sumber: Yamaha Music Foundation)

\section{Economic Movement}

Seorang pemain gitar klasik harus mampu mencari posisi penjarian yang baik dan efisien serta mampu mengatur jari-jari mana saja yang harus bergeser saat menemukan perpindahanperpindahan posisi yang sulit dan jarak yang jauh dalam memainkan sebuah komposisi. Dalam komposisi Gran Vals ini kemapuan jari-jari seorang pemain sangat diuji. Itu terbukti dibeberapa bagian komposisi dimana ada beberapa penjarian yang rumit, perpindahan yang cepat, perpindahan dengan bentuk akord yang sulit serta perpindahan yang harus menyambung diantara nada-nada tersebut. Bagian-bagian yang membutuhkan perpindahan posisi serta penjarian yang rumit iantaranya ialah sebagai berikut:

\section{Birama 46-47}

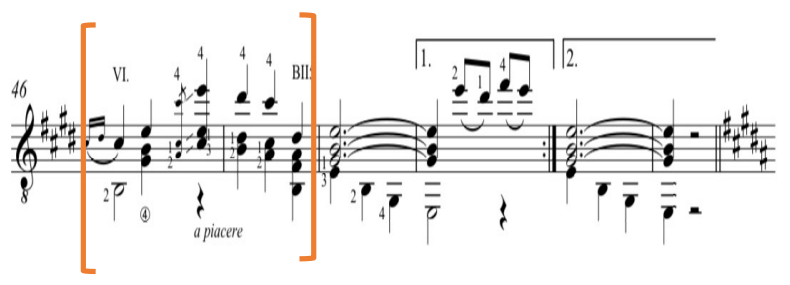

Gambar 9 (Teknik Penjarian) (Sumber: Bradford Warner Guitar Editions) 
Pada bagian ini ketepatan dan kecepatan perpindahan posisi jari-jari seorang pemain sangat menjadi faktor utama untuk bisa membawakan bagian ini dengan baik. Hal itu dikarenakan pada birama ke 46 ini ketukan pertama mempunyai posisi penjarian yang jauh dengan posisi penjarian ketukan not ke 2 sedangkan pada ketukan not kedua ini mengharuskan jari-jari bisa langsung menekan 3 notasi (akord) sekaligus dengan sempurna atau tepat hal itu agar irama tetap menyambung dan tidak putus. Selain itu jika diamati akord yang dimainkan pada ketukan ketiga birama 46 sampai dengan ketukan 1 dan 2 birama 47 itu mempunyai bentuk yang hampir sama sehingga penjarian seperti ini mengharuskan pemain bisa menganalisis dengan baik antara jari mana yang harus diangkat, jari mana yang harus tetap, jari mana yang hanya bergeser serta jari mana yang harus diganti dengan jari yang lain. Untuk mengatasi bagian sulit ini adalah dengan cara sebagai berikut: (1) Akord birama ke 46 ketukan kedua dibuat open string untuk nada B dan E. sehingga jari yang bebas bisa disiapkan untuk mengambil akord ketukan ke 3. (2) Memainkan kedua birama tersebut secara berulang-ulang hal ini bertujuan supaya jari kiri terbiasa memainkan perpindahan posisi tersebut. (3) Memainkan bagian ini dengan tempo yang lambat terlebih dahulu agar perpindahan posisi penjarian tepat pada notasi yang diinginkan dan suara yang dihasilkan jelas dan bersih. (4) Memainkan dengan menggunakan metronome untuk mengukur ketepatan pada setiap ketukan.

\section{Birama 63-64}

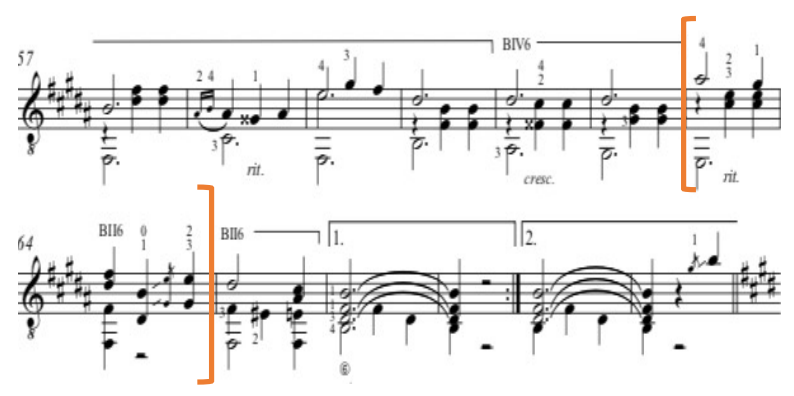

Gambar 10 (Teknik Shifting Position)

(Sumber: Bradford Warner Guitar Editions)

Pada bagian ini keefisiennan dan keefektifan penjarian seorang pemain sangat penting hal itu terkait dengan adanya bagian yang harus menyambung diantara kedua birama tersebut yaitu ketukan ketiga birama 63 dan ketukan pertama birama 64 yang cukup sulit jika dilihat dari bentuk penjarian yang terdapat dalam partitur karena kedua ketukan tersebut mempunyai teknik yang berbeda. Menurut Rahmat Raharjo dalam wawanacara pada tanggal 19 April 2019 untuk mengatasi bagian tersebut pemain harus mempunyai metode yang tepat agar bisa mempermudah penjariannya. Metode yang dapat digunakan di bagian ini ialah metode shifting position yaitu metode untuk mengatur jari-jari yang bergerak atau bergeser sehingga memudahkan penjarian kita serta mengefektifkan pergerakan tersebut. Dalam hal ini shifting position dapat dilakukan dengan menggunakan teknik barre. Shifting position menggunakan barre dapat kita lakukan di ketukan ke tiga pada birama sebelumnya agar nada tetap bisa menyambung dengan nada selanjutnya.

Birama 59-68

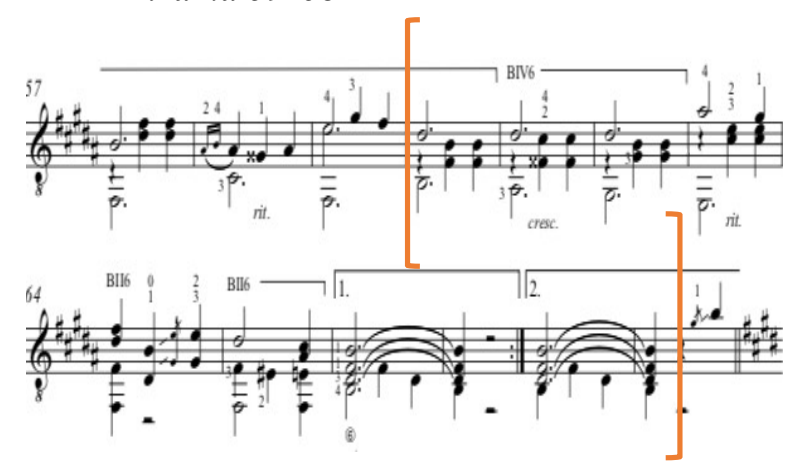

Gambar 11 (Teknik Permainan Barre) (Sumber: Bradford Warner Guitar Editions)

Pada bagian 59-68 ini teknik barre digunakan hampir disemua bagian tesebut. Yang menjadikan bagian ini sulit ialah teknik barre dalam bagian ini semuanya harus dimainkan menyambung antara satu dengan yang lainnya. Hal itu menuntut pemain harus teliti dan mempunyai 
kekuatan yang baik dalam melakukan teknik barre supaya nada yang dihasilkan tidak putus karena saat memainkan teknik tersebut kekuatan jari pemain juga harus dibagi pada jarijari yang lainnya yang juga harus memainkan notasi dengan posisi yang berbeda-beda. Selain itu bagian yang cukup sulit juga terletak pada perpindahan posisi dan bentuk penjariannya yaitu pada ketukan ke 3 birama 65 dan ketukan pertama birama 66. Posisi ini berupa perpindahan yang sama-sama menggunakan teknik barre namun mempunyai bentuk, posisi serta penjarian yang sangat berbeda. Untuk dapat mengatasi bagian sulit ini adalah dengan cara sebagai berikut: (1) Memainkan bagian ini berulang-ulang dengan tempo yang pelan sampai jari-jari terbiasa dan nyaman dengan posisi perpindahan penjarian dan bentuk tersebut. (2) Menguatkan teknik Barre dengan cara memaikan akord-akord yang menggunakan teknik tersebut sampai setiap senar dapat berbunyi dengan jelas. (3) Menguatkan teknik Barre dengan cara memainkan akord-akord yang berbeda-beda sampai dapat berpindahpindah posisi dengan baik.

\section{SIMPULAN}

Berdasarkan penelitian yang dilakukan mengenai komposisi Gran Vals karya Fransisco Tarrega ini maka dapat disimpulkan bahwa Gran Vals ini merupakan komposisi bentuk tunggal berirama waltz dengan 5 bagian didalamnya (A-BC-D-E) yang terdiri dari 119 birama. Deskripsi teknik permainan sulit yang terdapat dalam komposisi Gran Vals ini yaitu: (a)Kecepatan/speed dalam teknik slur merupakan bagian penting dalam komposisi ini. Teknik ini banyak digunakan terutama di bagian A dan B. (b) Power dalam teknik voiceing yaitu pembagian suara antara melodi utama dan melodi iringan yang digunakan di bagian C. (c) Economic Movement pada teknik barre serta keefisienan dan keefektifan penjarian yang hampir terletak di semua bagian komposisi ini.
Teknik-teknik permainan pada komposisi ini mempunyai dua fungsi dalam penggunaannya, yaitu: (1) Memperindah nada yang diproduksi yang diantaranya adalah: (a) Teknik Slur dalam komposisi Gran Vals yang berfungsi untuk memperindah permainan gitar serta menjadikan komposisi ini lebih ekspresif.(b) Teknik Voiceing dalam komposisi ini juga berfungsi untuk memperindah suara agar seimbang antara melodi dan iringan. (c) Teknik Glissando dan grace notes keduanya berfungsi untuk memperindah permainan gitar serta menjadikan komposisi ini lebih vareatif dan ekspresif. (2) Memudahkan pemain dalam memproduksi nada yang diantaranya adalah: (a) Teknik Barre berfungsi untuk mempermudah pemain dalam memproduksi nada teknik barre membantu pemain untuk menekan lebih dari satu senar hanya dengan satu jari. Ini memungkinkan jari lain dapat menekan posisi yang lain. Teknik ini juga membuat perpindahan akor pada satu lagu menjadi lebih sederhana. (b) Teknik memetik Apoyando dan Tirando kedua teknik ini berfungsi untuk mempermudah pemain dalam memainkan berbagai bentuk notasi baik yang berbentuk akord maupun solo atau tunggal

\section{DAFTAR PUSTAKA}

Iznaola, Ricardo. 2015. "khitarologus: The Path to Virtuosity”.

Kristianto, Jubing. 2013. “Gitarpedia”.Jakarta : PT Gramedia Pustaka Utama.

Kodijat, Latifah. 1986. "Istilah - istilah Musik". Jakarta : Djambatan.

Martopo, Hari. 2015. "Musik Barat Selayang Pandang”. Jakarta : Panta Rhei Books.

Prier, Karl Edmund SJ. 2009. "Kamus Musik”.'Yogyakarta: Pusat Musik Liturgi.

Sugiyono. 2011. "Metode Penelitian Liantitatif Kualitatif". Bandung : Alfabeta. 
Sugiyono. 2005. "Memahami Penelitian Kualitatif”. Bandung : CV Alvabeta.

Wicaksono, Herwin, Yogo. 2004. "Praktik Individual Mayor 1 Gitar”. Yogyakarta : Universitas Negeri Yogyakarta.

Widyatama, Sila. 2012. "Sejarah Musik dan Apresiasi Seni”. Jakarta : PT Balai Pustaka.

Werner, Bradford. 2019. “ Classical Guitar Metod Vol. 1". Canada : Werner Guitar Editions.

Suwahyono, A. (2018). CAPRICE NO. 24 KARYA PAGANINI PADA SOLO GITAR ARANSEMEN JOHN WILLIAMS (ANALISIS BENTUK MUSIK). Virtuoso (Jurnal Pengkajian dan Penciptaan Musik), 1(1), 24-29. 